\title{
Comparison of Post-Operative Lordosis with the PEEK Cage and the Cervical Plate
}

\author{
Jeffrey S. Wilkinson, Sumeer A. Mann, Grant W. Stoneham, Stephen Hentschel, \\ Daryl R. Fourney
}

\begin{abstract}
Objective: The maintenance of post-operative lordosis has been shown to be a key factor in decreasing adjacent level disc stress. Previous studies of the PEEK (polyetherether ketone) cage have used intervertebral bony fusion as the primary measure of surgical success; however, little is known about its effects on spinal curvature. Our objective was to compare the PEEK cage to the cervical plate with respect to the maintenance of cervical lordosis at one year. Secondary outcomes included fusion and complication rates. Methods: We performed a retrospective study of patients who underwent ACDF (anterior cervical discectomy and fusion) by two different methods; 13 patients were treated with the PEEK cage, and 22 with allograft and plating. Results: Patient and treatment characteristics were similar in both groups. Average global lordotic curvature (C2-C7) was increased by 1.7 degrees for the PEEK cage and decreased by 1.6 degrees for the plate after an average follow-up of 12.46 and 14.95 months, respectively. Regional lordosis for the PEEK cage and plate was decreased by 2.5 and 2.1 degrees, respectively for the same time period. These differences did not achieve statistical significance. Bony fusion was observed in all patients. One patient in each group developed persistent mild dysphagia. Conclusions: The PEEK cage is comparable to the anterior cervical plate in the maintenance of post-operative cervical lordosis.
\end{abstract}

RÉSUMÉ: Comparaison de la lordose post-opératoire selon qu'une cage en PEEK ou qu'une plaque d'ostéosynthèse cervicale est utilisée. Objectif : Il est bien connu que le maintien de la lordose post-opératoire est un facteur important pour diminuer le stress sur les disques des niveaux adjacents. Des études antérieures de la cage en PEEK (polyétheréthercétone) ont utilisé la fusion osseuse intervertébrale comme mesure primaire du succès chirurgical. Cependant, on sait peu de choses à propos de ses effets sur la courbature spinale. Notre objectif était de comparer la cage en PEEK à la plaque d'ostéosynthèse cervicale quant au maintien de la lordose cervicale un an plus tard. Les critères d'évaluation secondaires comprenaient la fusion et les taux de complications. Méthodes : Nous avons effectué une étude rétrospective des patients qui ont subi une discectomie avec fusion cervicale antérieure par deux méthodes différentes : 13 patients ont été traités au moyen de la cage en PEEK et 22 ont reçu une allogreffe avec pose d'une plaque d'ostéosynthèse. Résultats : Les caractéristiques des patients et du traitement étaient les mêmes dans les deux groupes. La courbature lordotique globale moyenne (C2-C7) était de 1,7 degré plus élevée dans le groupe chez qui la cage en PEEK avait été utilisée et diminuée de 1,6 degré dans le groupe chez qui une plaque d'osthéosynthèse avait été utilisée après un suivi moyen de 12,46 et de 14,95 mois respectivement. La lordose régionale était diminuée de 2,5 degrés dans le premier groupe et de 2,1 degrés dans le deuxième groupe après cette durée de suivi. Ces différences n'étaient pas significatives à l'analyse statistique. Tous les patients présentaient une fusion osseuse. Un patient de chaque groupe a présenté une dysphagie légère. Conclusions : La cage en PEEK est comparable à la pose d'une plaque d'ostéosynthèse cervicale antérieure pour le maintien de la lordose cervicale après la chirurgie.

Can. J. Neurol. Sci. 2011; 38: 72-77

The spinal column incorporates both lordotic and kyphotic curvatures to provide postural strength by maximizing the distribution of forces, and to facilitate its dynamic movement. Deformity can place uneven mechanical stress not only on the localized segment of the spine, but also throughout the entire spine - eventually contributing to disc degeneration. ${ }^{1}$ Adjacent segment degeneration can lead to neurological compromise or pain, ultimately requiring additional surgery. ${ }^{2}$ The restoration or maintenance of cervical lordosis may help to reduce the likelihood of adjacent segment degeneration. ${ }^{3}$ Anterior plating was introduced more than 20 years ago, partly as a means to help preserve post-operative lordosis. ${ }^{4}$

The PEEK cage (polyetherether ketone) is an intervertebral spacing biopolymer that employs vertical titanium spikes for enhanced stability. It is typically used as a "stand-alone" device. Recent investigations into the PEEK cage have shown fusion rates comparable to other methods of ACDF (anterior cervical discectomy and fusion). ${ }^{5-9}$ However, the ability of the PEEK

From the College of Medicine (JSW, SAM), Department of Diagnostic Imaging (GWS), Division of Neurosurgery (DRF), University of Saskatchewan, Saskatoon, Saskatchewan; Division of Neurosurgery (SH), Victoria, British Columbia, Canada Received March 4, 2010. Final Revisions Submitted June 30, 2010. Correspondence to: Daryl R. Fourney, Division of Neurosurgery, University of Saskatchewan, Royal University Hospital, 103 Hospital Drive, Saskatoon, Saskatchewan, S7N 0W8, Canada. 


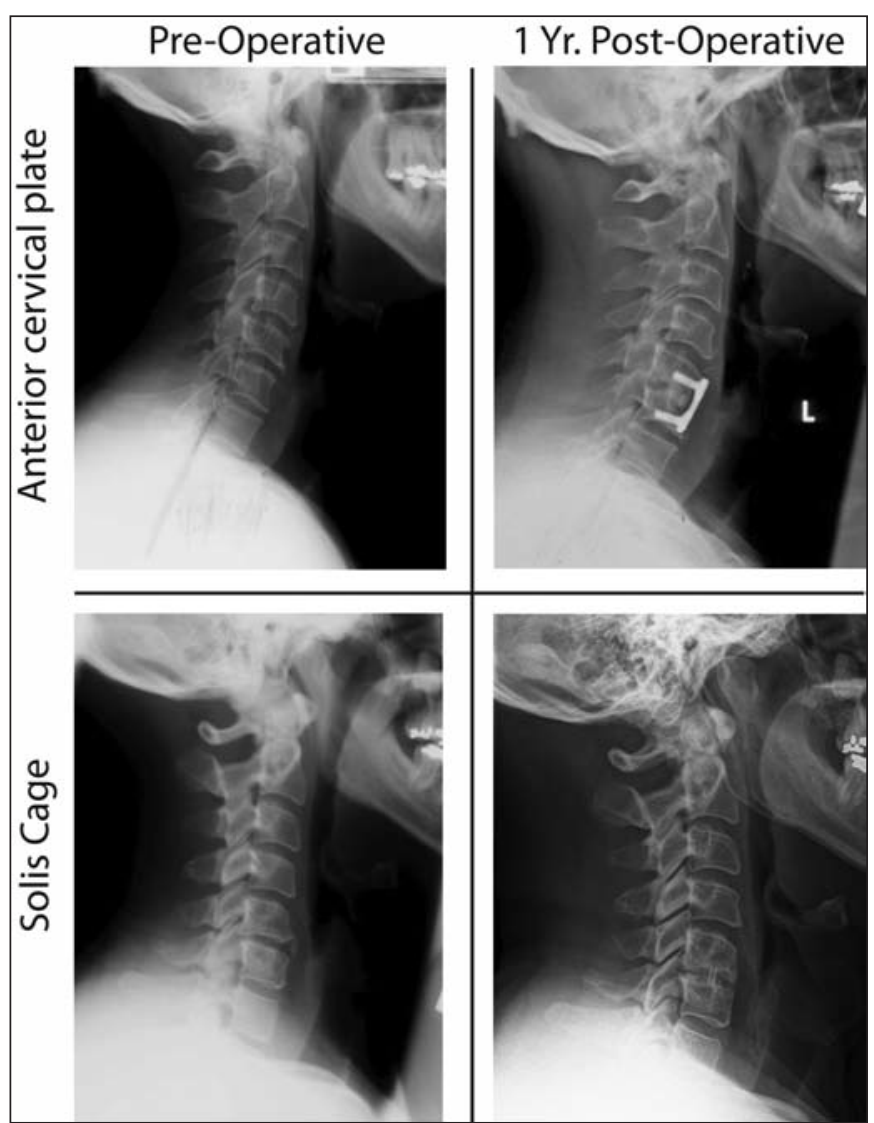

Figure 1: Lateral cervical spine radiographs of both the plate and PEEK cage group pre-operatively and in the long-term post-operative period.

cage to maintain post-operative lordosis has not been extensively studied.

We present, to the best of our knowledge, the first comparative analysis of cervical spinal alignment after ACDFP (anterior cervical discectomy and fusion with plating) versus the PEEK cage. The primary objective was to compare the PEEK cage to ACDFP with respect to the maintenance of cervical lordosis at one year. Secondary outcomes included fusion rate and the rate of complications.

\section{Clinical Materials and Methods}

This retrospective study was conducted under conditions approved by the medical ethics review board of the University of Saskatchewan and the Saskatoon Health Region.

\section{Patient Population}

All patients who underwent ACDF by the senior authors (SH and DF) at Royal University Hospital, Saskatoon, Saskatchewan, Canada between January 2003 and April 2006 for single or twolevel disc disease were identified by a review of our clinical database. We found 56 patients with neurologically symptomatic disc disease (i.e. radiculopathy or myelopathy) for which a 1 or 2 level discectomy was performed using either the PEEK cage or anterior cervical plate for stabilization. Patients with confounding variables (previous cervical spine surgery, trauma, or tumor), or unavailable imaging were not included. After application of these criteria, a total study population of 35 patients was reviewed. The indications for either ACDF were identical in each group; however, there was no randomization of subjects to either treatment.

\section{Surgical Procedure}

A right-sided Smith-Robinson technique of anterior cervical microdiscectomy was performed in all patients under general anesthesia.

For plated patients, the interbody fusion was routinely achieved with radius allograft (Anterior Cervical Fusion Spacer, Musculoskeletal Transplant Foundation, Edison, NJ) machined to 7 degrees of lordosis. Plating was performed with the Cervical Spine Locking Plate (Synthes, West Chester, PA).

In the comparison group, the PEEK cage (Solis cage, Stryker Spine, Kalamazoo, MI) with 4 degrees of lordosis was packed with local autograft. If the amount of material for grafting was insufficient, iliac crest autograft was used. The PEEK cage was routinely placed slightly anteriorly to the middle of the vertebral body. Plating was not performed in patients that received the PEEK cage.

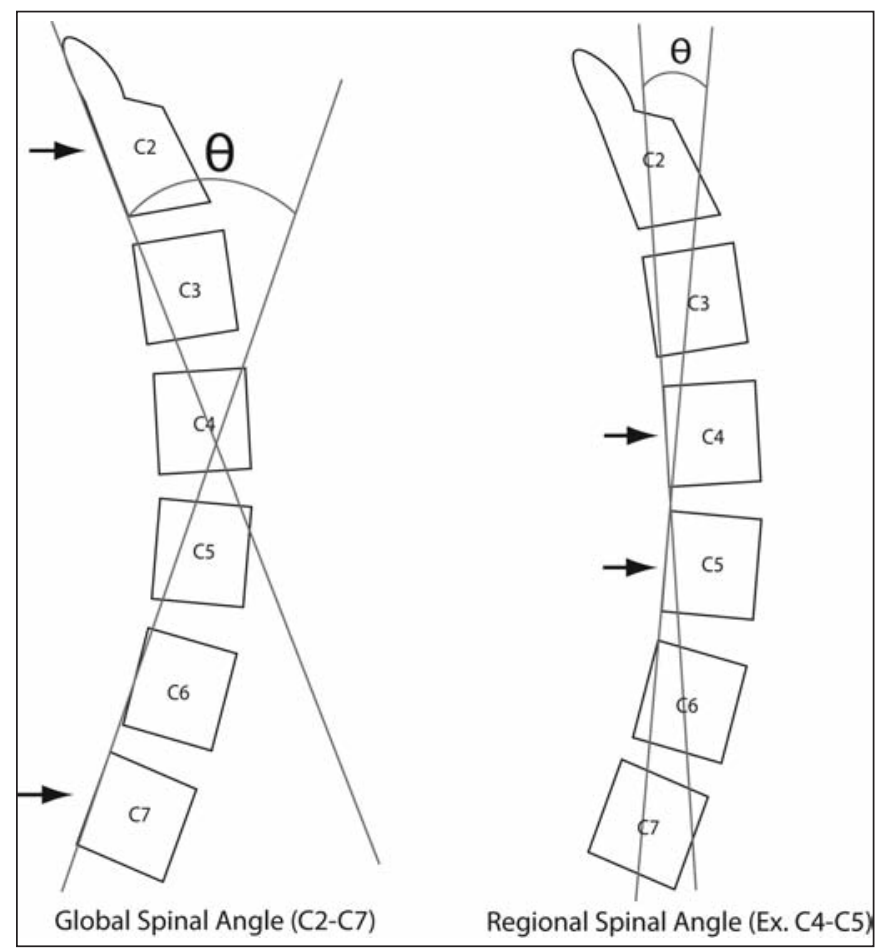

Figure 2: Diagrammatic representation of lateral cervical radiograph measurement - a modified version of the Cobb method. Tangents are drawn to the posterior aspect of the vertebral body at the levels of interest. The intersecting acute angle was then measured, represented by a negative value for lordosis, and a positive angle in the kyphotic spine. 
In both groups, the endplates were carefully preserved (i.e., prepared for fusion but not extensively drilled down). Collars were not employed after either type of fusion.

\section{Curvature Analysis of the Cervical Spine}

Pre-operative, early post-operative, and long-term ( $>1$ year) post-operative upright lateral cervical radiographs were collected for each patient to assess for changes in short-term and long-term cervical lordosis after ACDF (Figure 1). The change in cervical lordosis was assessed via a modification of the Cobb method, which uses a first derivative analysis as an exact measure of the cervical curvature through posterior tangents. ${ }^{10}$ Both the global (C2-C7) and regional spinal angles were analyzed (Figure 2). Tangents were drawn to the posterior vertebral body at the superior most level and at the inferior most level of interest. The acute angle was measured at the intersection of these tangents using a goniometer. Regional and global spinal angles have been shown to be more accurate than the Cobb method, as osteophyte formation may obscure the true location of the endplates. ${ }^{10}$

Lordosis was defined as greater than 5 degrees of lordosis across the $\mathrm{C} 2-\mathrm{C} 7$ segment. A neutral alignment was defined from 5 degrees lordosis to 5 degrees of kyphosis. Kyphotic deformity was defined as greater than 5 degrees of kyphosis across the $\mathrm{C} 2$ C7 segment.

Fusion was assessed by an independent observer (radiologist). The criteria for fusion included bony trabeculation across the graft and stability on flexion and extension views.

All statistical analysis was done using commercially available software, SPSS version 16.0 (Chicago, Illinois). Intra-group comparisons for spinal angle analysis were made using the nonparametric Wilcoxon signed-rank test. Comparisons between the

Table 1: Identifying data

\begin{tabular}{c|c|c|c}
\hline Characteristic & $\begin{array}{c}\text { Cervical Plate } \\
\mathbf{n = 2 2}\end{array}$ & $\begin{array}{c}\text { Solis Cage } \\
\mathbf{n = 1 3}\end{array}$ & p-value \\
\hline Mean Age (Range) & $48.2(35-65)$ & $49.2(38-60)$ & $0.80^{*}$ \\
\hline Sex & $\begin{array}{c}14(63.6 \%) \text { males; } \\
8(36.4 \%) \text { females }\end{array}$ & $\begin{array}{c}10(76.9 \%) \text { males; } \\
3(23.1 \%) \text { females }\end{array}$ & $0.48^{\prime}$ \\
\hline Smoking & $4(18.2 \%)$ & $2(15.4 \%)$ & $1.00^{\circ}$ \\
\hline Single-Level & $19(90.9 \%)$ & $10(76.9 \%)$ & \multirow{2}{*}{$0.65^{\prime}$} \\
\hline Two-Level & $3(9.1 \%)$ & $3(23.1 \%)$ & \\
\hline C4-C5 & $4(16.0 \%)$ & $2(12.5 \%)$ & $1.00^{\circ}$ \\
\hline C5-C6 & $11(44.0 \%)$ & $6(37.5 \%)$ & $0.75^{\prime}$ \\
\hline C6-C7 & $10(40.0 \%)$ & $8(50.0 \%)$ & $0.75^{\prime}$ \\
\hline $\begin{array}{c}\text { Total operated } \\
\text { levels }\end{array}$ & 25 & 16 & \\
\hline
\end{tabular}

Summary of patient characteristics of the plate and PEEK cage groups.

* Un-paired student's t-test; $†$ Fisher's exact test - two tailed

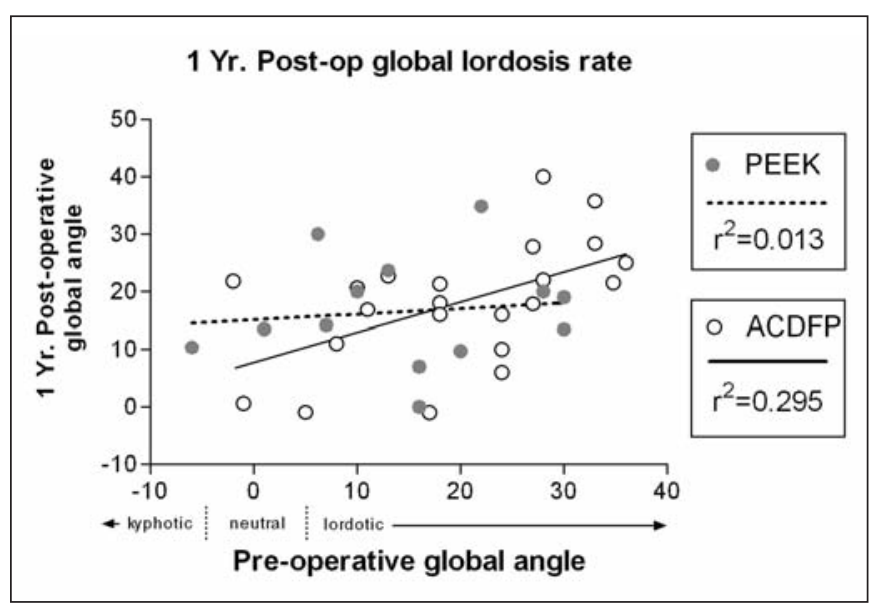

Figure 3: Pre-operative alignment was plotted against the long-term post-operative alignment for the plate and PEEK treated groups. A calculated linear regression line is drawn for comparison between the two groups.

plate and cage groups for spinal angles were made using the Mann-Whitney test for significance.

\section{RESULTS}

\section{Patient Characteristics}

Patient characteristics are summarized in Table 1 . Twentytwo patients $(63 \%)$ underwent ACDFP and 13 (37\%) received the PEEK cage. Although most patients had a 1-level procedure, the plate and PEEK group each included 3 two-level procedures. In total, 41 cervical levels were studied. Both groups studied did not have statistically different relevant characteristics (Table 1).

\section{Spinal Alignment Data}

The average time from surgery until the early post-operative cervical radiograph for the plate and cage group was 1.63 months (range: 1 to 3 months) and 1.92 months (range: 1 to 4 months), respectively ( $\mathrm{p}=0.26$, unpaired student's t-test). The average time from surgery until the long-term post-operative radiograph for the plate and cage group was 14.95 months (range: 6-36 months) and 12.46 months (range: 9 to 15 months), respectively ( $\mathrm{p}=0.40$, unpaired student's t-test).

The pre-operative global alignment of both groups was highly diverse (Figure 3). This heterogeneous population, however, was valuable in studying both the plate and the cage because instrumentation can have varying effects on spinal curvature depending on differences in the pre-operative alignment. This heterogeneous group is best displayed using an XY scatter plot. Figure 3 includes a plot of long-term postoperative curvature against pre-operative curvature for both the plate and cage groups. Both plots include a calculated linear regression line for comparison.

Table 2 summarizes pre- and post-operative regional lordosis in both groups. Both patient groups had very similar amounts of pre-operative regional lordosis: -2.3 and -2.5 degrees, respectively ( $\mathrm{p}=0.737$, Mann-Whitney test). Early post-operative 
Table 2: Spinal alignment data

\begin{tabular}{|c|c|c|c|c|}
\hline & & Pre-operative & $\begin{array}{c}\text { Early } \\
\text { post-operative }\end{array}$ & $\begin{array}{l}\text { Long-term (>1 yr.) } \\
\text { post-operative }\end{array}$ \\
\hline \multirow{2}{*}{ Cervical Plate } & $\begin{array}{c}\text { Regional } \\
(n=25)\end{array}$ & $\begin{array}{l}-2.3 \\
\pm 5.3\end{array}$ & $\begin{array}{l}-2.9 \\
\pm 4.7\end{array}$ & $\begin{array}{l}-0.2 \\
\pm 5.4\end{array}$ \\
\hline & $\begin{array}{l}\text { Global } \\
(n=22)\end{array}$ & $\begin{array}{l}-19.7 \\
\pm 11.2\end{array}$ & $\begin{array}{l}-18.4 \\
\pm 12.0\end{array}$ & $\begin{array}{l}-18.1 \\
\pm 10.7\end{array}$ \\
\hline \multirow{2}{*}{ Solis Cage } & $\begin{array}{c}\text { Regional } \\
(n=16)\end{array}$ & $\begin{array}{l}-2.5 \\
\pm 6.4\end{array}$ & $\begin{array}{l}-0.7 \\
\pm 3.9\end{array}$ & $\begin{array}{c}0.0 \\
\pm 4.2\end{array}$ \\
\hline & $\begin{array}{l}\text { Global } \\
(n=13)\end{array}$ & $\begin{array}{l}-14.9 \\
\pm 11.2\end{array}$ & $\begin{array}{l}-14.7 \\
\pm 12.0\end{array}$ & $\begin{array}{l}-16.6 \\
\pm 9.4\end{array}$ \\
\hline
\end{tabular}

Summary of regional and global spinal angles of the plate and PEEK cage groups pre-operatively, early post-operatively, and long-term ( $>1$ yr.) post-operatively.

regional lordosis was slightly increased in the plate group at -2.9 degrees ( $\mathrm{p}=0.594$, Wilcoxon test). The cage group showed an early decrease in regional lordosis of 2.2 degrees with an average early regional lordosis of -0.7 degrees $(p=0.209$, Wilcoxon test). Over the long-term follow-up, the regional lordosis of the plate group decreased to -0.2 degrees ( $\mathrm{p}=0.179$, Wilcoxon test), while in the cage group, regional lordosis decreased only slightly to 0.0 degrees ( $\mathrm{p}=0.127$, Wilcoxon test).

Table 2 also summarizes pre- and post-operative global lordosis in both groups. The pre-operative global curvature (C2C7) for the plate and cage group was -19.7 (range: -36 to +2 ) and

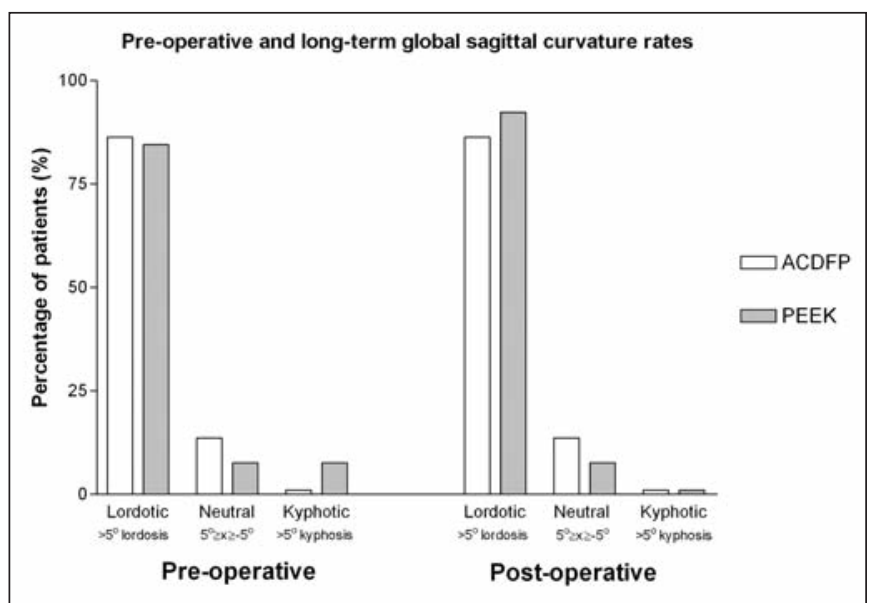

Figure 4: A comparison of the number of globally lordotic patients preoperatively and in the long-term post-operative period for both the plate and PEEK cage treated groups. Global lordosis was defined as greater than 5 degrees of lordosis (> +5). Neutral alignment is defined as between 5 degrees of lordosis and 5 degrees of kyphosis. Kyphotic deformity is defined as greater than 5 degrees of kyphosis.
-14.9 (range: -30 to +6 ) degrees of lordosis, respectively. These values were not statistically different $(\mathrm{p}=0.232$, Mann-Whitney test). Early post-operative curvature was -18.4 (range: -34 to +8 ) and -14.7 (range: -34 to +14 ) degrees of lordosis for the plate and cage groups, respectively. These values were also not statistically different ( $\mathrm{p}=0.462$, unpaired t-test). Thus, both groups showed a small degree of loss of cervical lordosis after surgery, both regionally and globally. On long-term analysis, global curvature in the plate group did not show a significant decrease in lordosis. The plate group maintained a lordotic curve of -18.1 degrees - a loss of 1.6 degrees ( $\mathrm{p}=0.375$, Wilcoxon test). However, the cage group showed an overall increase in lordosis over the same period. Compared to the pre-operative analysis, the cage group gained 1.7 degrees, attaining an overall -16.6 degrees of lordosis after one year ( $\mathrm{p}=0.650$, Wilcoxon test).

In the plate treated group, one patient lost lordotic alignment and fell into the neutral category, while another patient gained an overall global lordosis. This resulted in no change from the preto post-operative categorization of alignment (Figure 4). In comparison, one patient from the PEEK treated group gained overall lordosis, with one patient maintaing overall neutral alignment (Figure 4). Regionally, one patient in the plate group became kyphotic (defined as greater than 5 degrees of kyphosis). There was also one patient in the PEEK group that had persistent regional kyphosis of the operated level.

A retrospective power analysis was able to yield a study power of 0.10 . Thus, in order to find a significant difference between the groups, a very large number of patients (approximately 1000) would be required to find a statistical difference.

\section{Fusion and Surgical Complications}

Fusion was observed in all patients reviewed in both the plate and cage groups. None of the patients required revision surgery. Four patients in the plate group complained of mild dysphagia immediately post-operatively, which all resolved within one month except for one which resolved by six months. One patient in the cage-treated group reported persistent dysphagia beyond one year.

\section{Discussion}

There is still debate over the need for instrumentation after anterior cervical discectomy. Some surgeons feel that plating is necessary to help prevent or correct sagittal deformity, increase the chance of a successful fusion, and to avoid the use of restrictive collars in the post-operative period. ${ }^{11,12}$ Potential complications of cervical plates include hardware failure, esophageal irritation, increased procedure time, and cost. Some surgeons continue to prefer the non-instrumented ACDF in most cases, citing comparable rates of fusion and clinical outcomes. ${ }^{9}$ However, there is some evidence that non-instrumented ACDF has a greater tendency to lead to kyphotic deformity. ${ }^{13}$ Surgeons who routinely employ an anterior cervical plate may be reluctant to use a stand-alone device because of the risk of post-operative kyphosis.

With regards to measures of success after ACDF, sagittal alignment has not been as closely studied as the rate of fusion because deformity has not shown a consistent relationship with clinical outcomes in the short term (i.e., kyphosis or subluxation 
do not always cause pain). However, the importance of maintaining cervical lordosis after ACDF may be more important in the long-term. The rate of adjacent level disc degeneration ten years after single-level ACDF is roughly $25 \%{ }^{2}$ It has been proposed that accelerated spinal degeneration is related to the increased range of motion (ROM) of spinal levels adjacent to the fusion. ${ }^{14} \mathrm{~A}$ recent in vivo study examining adjacent level strain after fusion found that a greater postoperative lordotic curvature was able to decrease adjacent level ROM. ${ }^{15}$ This decrease in mechanical demand may help to preserve adjacent levels, even many years after surgery. In a similar biomechanical study, kyphotic deformity caused increased ligamentous strain, facet osteoarthritis, and uneven load transmission throughout the spine. ${ }^{15}$

Kyphotic deformity also correlates with chronic neck pain. Patients with less than 20 degrees of lordosis have a significant increase in neck pain complaints. ${ }^{16}$ As well, there is some evidence that malalignment of the spine may impact regional blood flow and compromise the integrity of the spinal cord in the long-term. ${ }^{11}$

It is clear that the maintenance of cervical lordosis must be considered when comparing different surgical techniques for ACDF. Currently, few studies have included a detailed analysis of alignment when assessing the efficacy of the PEEK cage. $6,7,17,18$

The purpose of this study was to compare the PEEK cage to the cervical plate in maintenance of cervical alignment postoperatively. To improve accuracy, we chose to use posterior vertebral body tangents to determine regional and global spinal angles rather than the traditional Cobb method. However, our results are still comparable to Cobb angle studies. Cobb angles are mathematically identical to the angles obtained using the posterior method. The benefit of using the posterior vertebral body rather than the endplates is that the endplate may be obscured by osteophyte formation. Most patients studied were over 50 years-of-age and had varying degrees of cervical spondylosis.

Our results have been able to confirm the results of previous studies, showing that the anterior cervical plate holds global lordosis at one year. ${ }^{9}$ As well, the plate had a zero incidence rate of global kyphotic deformity. By comparison, the PEEK cage was equally effective at holding global lordosis and maintenance of alignment after one year. Based on the minimalist design of the cage, we had expected a loss of cervical lordosis similar to previous studies of lone interbody spacers. ${ }^{13}$ Based on these results, it appears that long-term degenerative changes at adjacent levels may be similar between the PEEK cage and anterior cervical plate based on the importance of cervical lordosis on adjacent level disc disease. A long-term prospective study would be necessary to confirm this.

We also analyzed fusion. Recent analyses have shown that almost all combinations of hardware and graft material results in fusion rates above 90\%., $9,12,18-20$ Our results have confirmed previously reported high rates of fusion using either the plate with allograft or the PEEK cage with local autograft. ${ }^{18,19}$

A limitation of this study is the small number of subjects. Based on the results in this small group of patients, we performed a power analysis and showed that we would need approximately 1000 patients in each group to show a statistically significant difference. As such, even a much larger study than ours would be unlikely to show a clinically important difference between groups. Another limitation is that because of rotational issues pertaining to patient and collimator positioning, the accuracy of angular measurements made from plain films is limited. In terms of clinical utility, recent work has estimated that a $95 \%$ confidence interval for intra and interobserver variability was 3 to 7 degrees, respectively. ${ }^{21}$

\section{CONCLusion}

The human spinal column is designed with lordotic and kyphotic curvatures to provide postural strength by maximizing the distribution of forces, and to facilitate its dynamic movement. The long-term success of spinal surgery appears to be dependent on the maintenance of these curvatures. ${ }^{3}$ Our results suggest that the ACDF performed with the PEEK cage (as a stand-alone device) is similar to anterior cervical plating, with respect to sagittal alignment, fusion, and complication rates.

\section{FUNDING}

This work was supported by funding from the University of Saskatchewan, College of Medicine.

\section{REFERENCES}

1. Hwang SH, Kayanja M, Milks RA, Benzel EC. Biomechanical comparison of adjacent segmental motion after ventral cervical fixation with varying angles of lordosis. Spine J. 2007;7(2): 216-21.

2. Hilibrand AS, Carlson GD, Palumbo MA, Jones PK, Bohlman HH. Radiculopathy and myelopathy at segments adjacent to the site of a previous anterior cervical arthrodesis. J Bone Joint Surg Am. 1999;81(4):519-28.

3. Katsuura A, Hukuda S, Saruhashi Y, Mori K. Kyphotic malalignment after anterior cervical fusion is one of the factors promoting the degenerative process in adjacent intervertebral levels. Eur Spine J. 2001;10(4):320-4.

4. Moftakhar R, Trost GR. Anterior cervical plates: a historical perspective. Neurosurg Focus. 2004;16(1):E8.

5. Boakye M, Mummaneni PV, Garrett M, Rodts G, Haid R. Anterior cervical discectomy and fusion involving a polyetheretherketone spacer and bone morphogenetic protein. J Neurosurg Spine. 2005;2(5):521-5

6. Kulkarni AG, Hee HT, Wong HK. Solis cage (PEEK) for anterior cervical fusion: preliminary radiological results with emphasis on fusion and subsidence. Spine J. 2007;7(2):205-9.

7. Liao JC, Niu CC, Chen WJ, Chen LH. Polyetheretherketone (PEEK) cage filled with cancellous allograft in anterior cervical discectomy and fusion. Int Orthop. 2008;32(5):643-8.

8. Mastronardi L, Ducati A, Ferrante L. Anterior cervical fusion with polyetheretherketone (PEEK) cages in the treatment of degenerative disc disease. Preliminary observations in 36 consecutive cases with a minimum 12-month follow-up. Acta Neurochir (Wien). 2006;148(3):307-12; discussion 312.

9. Mobbs RJ, Rao P, Chandran NK. Anterior cervical discectomy and fusion: analysis of surgical outcome with and without plating. J Clin Neurosci. 2007;14(7):639-42.

10. Harrison DE, Harrison DD, Cailliet R, Troyanovich SJ, Janik TJ, Holland B. Cobb method or Harrison posterior tangent method: which to choose for lateral cervical radiographic analysis. Spine. 2000;25(16):2072-8.

11. Ferch RD, Shad A, Cadoux-Hudson TA, Teddy PJ. Anterior correction of cervical kyphotic deformity: effects on myelopathy, neck pain, and sagittal alignment. J Neurosurg. 2004;100(1 Suppl Spine):13-9.

12. Fraser JF, Hartl R. Anterior approaches to fusion of the cervical spine: a metaanalysis of fusion rates. J Neurosurg Spine. 2007; 6(4):298-303. 
13. Laing RJ, Ng I, Seeley HM, Hutchinson PJ. Prospective study of clinical and radiological outcome after anterior cervical discectomy. Br J Neurosurg. 2001;15(4):319-23.

14. Eck JC, Humphreys SC, Lim TH, et al. Biomechanical study on the effect of cervical spine fusion on adjacent-level intradiscal pressure and segmental motion. Spine. 2002;27(22):2431-4.

15. Oda I, Cunningham BW, Buckley RA, et al. Does spinal kyphotic deformity influence the biomechanical characteristics of the adjacent motion segments? An in vivo animal model. Spine. 1999;24(20):2139-46.

16. McAviney J, Schulz D, Bock R, Harrison DE, Holland B. Determining the relationship between cervical lordosis and neck complaints. J Manipulative Physiol Ther. 2005;28(3):187-93.

17. Celik SE, Kara A, Celik S. A comparison of changes over time in cervical foraminal height after tricortical iliac graft or polyetheretherketone cage placement following anterior discectomy. J Neurosurg Spine. 2007;6(1):10-6.
18. Cho DY, Liau WR, Lee WY, Liu JT, Chiu CL, Sheu PC. Preliminary experience using a polyetheretherketone (PEEK) cage in the treatment of cervical disc disease. Neurosurgery. 2002;51(6): 1343-49; discussion 9-50.

19. Samartzis D, Shen FH, Lyon C, Phillips M, Goldberg EJ, An HS . Does rigid instrumentation increase the fusion rate in one-level anterior cervical discectomy and fusion? Spine J. 2004;4(6): 636-43.

20. Samartzis D, Shen FH, Goldberg EJ, An HS. Is autograft the gold standard in achieving radiographic fusion in one-level anterior cervical discectomy and fusion with rigid anterior plate fixation? Spine. 2005;30(15):1756-61.

21. Silber JS, Lipetz JS, Hayes VM, Lonner BS. Measurement variability in the assessment of sagittal alignment of the cervical spine: a comparison of the Gore and Cobb methods. J Spinal Disord Tech. 2004;17(4):301-5. 